\title{
Abnormal movements associated with severe hyponatraemia
}

\author{
Nages Nagaratnam, Evelyn Icao, Helen Peric
}

\begin{abstract}
Summary
An elderly woman with severe hyponatraemia manifested transient choreoathetoid movements of the upper extremities and dyskinetic movements of the face and mouth. She showed more than one type of hyponatraemia and a precise diagnosis was not possible. The movements were abolished with treatment of the hyponatraemia with no recurrence or sequelae.
\end{abstract}

Keywords: hyponatraemia, diuretic, abnormal movements

Hyponatraemia (serum sodium level $<130$ $\mathrm{mmol} / \mathrm{l}$ ) is the most common electrolyte abnormality, especially in the elderly, and occurs with a wide variety of medical conditions. Asymptomatic hyponatraemia often goes undetected and with severe hyponatraemia the clinical presentation can be diverse and nonspecific such that early recognition can be delayed. ${ }^{1} \mathrm{~A}$ wide variety of neurological manifestations has been associated with hyponatraemia and severe hyponatraemia can have damaging effects on the central nervous system. ${ }^{2}$ Generalised disturbances such as inappropriate behaviour, hallucinations (both visual and auditory), unresponsiveness, seizures, and coma are the more frequent manifestations. ${ }^{3}$ We describe an elderly woman with severe hyponatraemia with choreo-athetoid and dyskinetic movements.

Department of Medicine (Geriatrics), Blacktown Hospital, NSW 2148 Australia N Nagaratnam E Icao

University of Sydney, Sydney, Australia

H Peric
- nausea, anorexia

- thirst, cramps

- poor skin turgor

- postural hypotension

\section{Case report}

A 77-year-old woman presented with intermittent dizziness and vomiting for over three months which had worsened over the past week. She was said to have Ménière's disease and had been on nicotinic acid, a combined diuretic (amiloride and hydrochlorothiazide) and prochlorperazine (5 mg tid) for several weeks. The subsequent diagnosis was benign paroxysmal positional vertigo. The medical history was of no clinical significance, but for diet-controlled diabetes. She had never been on neuroleptics and is a non-drinker and a non-smoker.

On admission the vital signs were unremarkable. The cardiovascular, respiratory and central nervous system were normal. The serum sodium was $134 \mathrm{mmol} / 1$, potassium $3.1 \mathrm{mmol} /$ 1, blood glucose $11.1 \mathrm{mmol} / \mathrm{l}$, calcium $2.37 \mathrm{mmol} / 1$, magnesium $0.62 \mathrm{mmol} / 1$, urea $5.8 \mathrm{mmol} / \mathrm{l}$ and creatinine $6.5 \mu \mathrm{mol} / \mathrm{l}$. Computed tomography (CT) scan of the brain was normal. She remained on the diuretic and prochlorperazine. Four days following admission vomiting worsened and three days later she was found groaning at $08.00 \mathrm{~h}$. She was conscious, but did not respond to verbal commands. She had mouthing movements involving the face, mouth and tongue, simulating tardive dyskinesia and writhing with sudden jerky movements of the upper limbs. The lower limbs were in extension with slight increase in tone. The pupils were equal and reactive. The plantars were flexor. There were no abnormalities in the other systems. The chest X-ray was normal. Routine haematology and liver function tests were normal. Her medications were stopped.

By $11.00 \mathrm{~h}$ her level of consciousness had worsened. She was unresponsive, but the movements continued and the plantars were extensor. The serum sodium level was found to be $101 \mathrm{mmol} / 1$, potassium $3.7 \mathrm{mmol} / \mathrm{l}$, urea $6.2 \mathrm{mmol} / \mathrm{l}$, creatine $68 \mu \mathrm{mol} / \mathrm{l}$, plasma osmolality $217(275-295) \mathrm{mosm} / \mathrm{kg}$, glucose $12.2 \mathrm{mmol} / \mathrm{l}$, cholesterol $4.5 \mathrm{mmol} / 1$, triglycerides $\quad 2.8 \quad(0.1-1.85) \mathrm{mmol} / \mathrm{l}$, sodium $117 \mathrm{mmol} / \mathrm{l}$, potassium $6.1 \mathrm{mmol} / \mathrm{l}$, urine osmolality $478(300-600) \mathrm{mosm} / \mathrm{kg}$. CT scan of the brain revealed no abnormality. She was commenced on normal saline. She had a generalised seizure, but was not given anticonvulsants. At $20.00 \mathrm{~h}$ she was still unconscious, the plantars were flexor and no movements were seen. Her serum sodium was $112 \mathrm{mmol} / \mathrm{l}$. She was then given $3 \%$ 
sodium chloride $500 \mathrm{ml}$ over $10 \mathrm{~h}$ and by $24.00 \mathrm{~h}$ the sodium was $116 \mathrm{mmol} / \mathrm{l}$, potassium $3.7 \mathrm{mmol} / \mathrm{l}$.

On day 2, her level of consciousness had improved. The serum sodium was $118 \mathrm{mmol} / \mathrm{l}$, potassium $2.6 \mathrm{mmol} / \mathrm{l}$ and magnesium 0.58 $\mathrm{mmol} / \mathrm{l}$. The last two were included in the infusion. Normal saline was then commenced, a litre 8-hourly. After $48 \mathrm{~h}$, serum sodium was $124 \mathrm{mmol} / \mathrm{l}$, potassium $3.4 \mathrm{mmol} / \mathrm{l}$ and magnesium $1.09 \mathrm{mmol} / 1$. On day 3 , she opened her eyes spontaneously and responded to verbal commands. There were no focal or lateralising neurological signs. Thereafter her condition improved and remained stable and on day 7 her sodium was $136 \mathrm{mmol} / 1$ and potassium $4 \mathrm{mmol} / \mathrm{l}$; she was mobilising independently and was discharged home on day 11. Blood sugar levels from days 1 to 11 ranged from 3.0$12.2 \mathrm{mmol} / 1$ with no treatment. She was prescribed prochlorperazine (Stemetil) with no recurrence of symptoms. When reviewed six weeks later there was no overt abnormality and prochlorperazine was stopped. On further follow-up over 18 months she remained well and her blood sugar was $5.5 \mathrm{mmol} / \mathrm{l}$.

\section{Discussion}

Our patient had severe hyponatraemia (serum sodium $101 \mathrm{mmol} / \mathrm{l}$ ) with abnormal movements. She responded to sodium replacement with a correction of $24 \mathrm{mmol} / \mathrm{l}$ in the first $48 \mathrm{~h}$. She recovered without any recurrence or sequelae. She had been on a combined diuretic until the onset of the abnormal movements.

More than one type of hyponatraemia could have contributed to her clinical state. The biochemical findings at the onset were that of the syndrome of inappropriate secretion of antidiuretic hormone (SIADH). SIADH is common in the elderly and has many causes (eg, infection/malignancy), although there was no obvious cause in our patient other than for

\begin{tabular}{|l|}
\hline Symptomatic hyponatraemia \\
\hline Investigations \\
- serum sodium \\
- serum sodium concentration \\
- urea and creatinine \\
- plasma osmolality \\
Treatment \\
- aim of treatment is a sodium concentration of \\
- correction of not more than $25 \mathrm{mmol} / 48 \mathrm{~h}$ \\
\hline
\end{tabular}

1 Booker JA. Severe symptomatic hyponatraemia in elderly outpatient. $\mathcal{f ~ A m ~ G e r i a t r ~ A s s o c ~ 1 9 8 4 ; ~ 3 2 : ~} 108$.

2 Arieff AI, Llach F, Massary SL, Kerian A. Neurologica manifestations and morbidity of hyponatraemia: correlation with brain water and electrolytes. Medicine (Baltimore) 1976 55: $121-9$.

3 Arieff AI. Management of hyponatraemia, fortnightly review. BMF 1993; 309: 305-8.

4 Tien R, Arieff AI, Kucharczyk W, Wasik A, Kucharczyk J. Tien R, Arieff AI, Kucharczyk W, Wasik A, Kucharczyk J.

5 Sethi KD, Nichols FT, Yaghmai F. Generalised chorea due

to basal ganglia lacunar infarcts. Mov Disord 1987; 2: 61-6. the thiazide therapy. There are, however, other mechanisms which may have contributed in some degree to the hyponatraemia, namely (a) the intractable vomiting and diuretic, (b) hyperglycaemia, and possibly (c) pseudohyponatraemia due to mildly elevated triglycerides.

It had been suggested that rapid correction of the hyponatraemia could lead to central pontine myelinolysis. It is now accepted that central pontine myelinolysis is almost never seen with hyponatraemia and is associated with medical conditions such as alcoholism, sepsis, advanced liver disease or malignancies. ${ }^{3}$ In hyponatraemia the observed lesions were diffuse areas of cerebral infarction. The rate of correction is said not to be a factor in the genesis of hyponatraemic brain injury but the absolute increase should be within $25 \mathrm{mmol} / \mathrm{l}$ in the first $48 \mathrm{~h}$ of treatment. ${ }^{3}$ Brain damage often occurs in untreated patients with hyponatraemia. ${ }^{2}$ Two different mechanisms induce brain injury in hyponatraemic patients, one associated with treatment and the other unrelated to it. ${ }^{4}$ In severe hypernatraemia cerebral hypoxia results from swelling of the brain and an increase in intracranial pressure giving rise to a reduction in cerebral blood flow and pressure of the brain against the rigid skull. ${ }^{4}$ In hyponatraemia, neuroimaging and autopsy findings have demonstrated infarction.

Tardive dyskinesia may develop with prochlorperazine and the risk increases with duration of the treatment (cumulative dose) and less commonly after brief treatment at low doses. In our patient the syndrome occurred acutely with no recurrence on re-commencement of the medication. It seems most unlikely that the abnormal movements were caused by prochlorperazine. Sethia et $a \bar{P}$ have described generalised chorea due to basal ganglia infarcts and they postulated that ischaemia rather than infarction gives rise to the movements. Abnormal and involuntary flinging movements, principally unilateral, of sudden onset lasting a few hours have been described with a striatal infarct. ${ }^{7}$ Episodic dyskinesias have been documented with cerebral ischaemia ${ }^{6}$ and are a rare manifestation of transient ischaemic attack in the carotid artery territory. Choreothetosis has been reported after insulin-induced hypoglycaemia $^{8}$ and with non-ketotic hyperosmolar coma. ${ }^{9}$

In conclusion, it is hypothesised that the transient hypoxia and ischaemia that occurs with severe hyponatraemia could affect the basal ganglia and give rise to abnormal movements. Although the CT scan was normal, CT is not particularly sensitive at identifying lesions in the region of the basal ganglia.

6 Margolin DI, Marsden CD. Episodic dyskinesias and transient cerebral ischaemia. Neurology 1982; 32: 1379-80. 7 Defebvre L, Destec A, Cassim F, Muller JP, Vermersch E. Transient hemiballism and frontal infarct (letter). Stroke 1990; 21: $967-8$.

8 Newman RP, Kinkel WR. Paroxysmal choreoathetosis due to hypoglycaemia. Arch Neurol 1974; 41: $341-2$

9 Rector WG, Herlong HF, Moses H. Non-ketotic hyperglyRector WG, Herlong HF, Moses H. Non-ketotic hypergly-
caemia appearing as choreoathetosis or ballism. Arch Intern Med 1982; 142: 154-5. 